\title{
CORRESPONDENCE.
}

\section{TWO POINTS IN THE TEACHING OF ELEMENTARY GEOMETRY.}

[The opinion of teachers on the points raised by Prof. Lodge's letter would be of great interest and a reply form is enclosed in each copy of the Gazette. These should be sent to Professor Lodge, 330 Banbury Road, Oxford; they will then be classified and a report published in the Gazette.]

To the Editor of the Mathematical Gazette.

SIR,--(1) I wish there could be a consensus of opinion as to which area propositions should be considered as fundamental in the First Book.

Of course, the areas of congruent triangles are equal, and incidentally, therefore, the diagonal of a parallelogram bisects its area.

After that, to my mind, the fundamental proposition should be that the areas of parallelograms on the same base and between the same parallels (of which the base is one) are equal in area. All the rest are immediate deductions. The order does not much matter, but for its importance in practice the second theorem should be that triangles on the same base and between the same parallels are equal in area, proved by completing the parallelograms of which the triangles are each obviously half. There is a tendency to make the rectangle the basis and to equate parallelograms to rectangles, and triangles to half-rectangles, so as to bring in the mensuration "base times height" business. My own feeling is that we should start with the more general propositions above as the foundation, with mensuration as a corollary or consequence. The Geometry Report, pp. 50, 51, strikes a double note; but a consensus of opinion seems desirable.

(2) Do teachers insist on their pupils quoting congruent or similar triangles with the angular points given in corresponding order, and preferably one below the other? Thus in the figure :

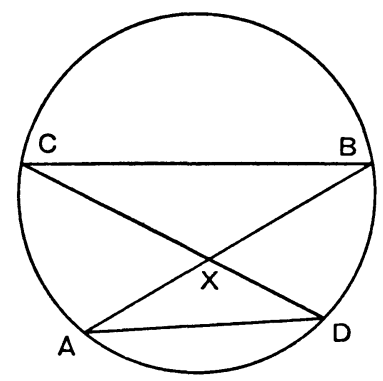

The triangles $\left|\begin{array}{l}C B X \\ A D X\end{array}\right|$ are similar in that order; hence $\frac{C B}{A D}=\frac{B X}{D X}=\frac{C X}{A X}$ if all three fractions are wanted, the numerators being taken from the first triangle in any order, and the denominators, in corresponding order, from the second triangle. If only two fractions are needed, we can either take numerators from one, and denominators from the other, as above, or one fraction from one triangle, and the corresponding fraction from the other, thus :

$$
\overline{B X}=\frac{A X}{D X} \text {. }
$$

In any case, the quoting in order of equal angles makes the taking of equal ratios definite and orderly without even having again to look at the figure.

I would be pleased to receive replies, assort them, and report on the result.-

Alfred LODge.

PRINTED IN GREAT BRITAIN BY ROBERT MACLFHOSE AND C'O. LTD.

THE UNIVERSITY PRESS, GLASGOW. 